\title{
Espíritus, escrituras y culto espiritual en la Antigüedad
}

\author{
Spirits, scriptures \\ and spiritual worship in antiquity \\ JACINTO CHOZA ARMENTA \\ Universidad de Sevilla, España \\ ANANÍ GUTIERREZ AGUILAR \\ Universidad Nacional de San Agustín, Arequipa, Perú
}

Recibido: 12/02/2019 Aceptado: 19/02/2019

\section{RESUMEN}

En la antigüedad, en la era axial, tiene lugar la madurez del espíritu (pneuma) y del intelecto (nous) y la generalización de la escritura. Entonces la religión, que tenía la forma del rito, de la ley y de la doctrina, adopta la forma del culto interior.

PALABRAS CLAVE

PNEUMA, NOUS, ESPÍRITU, INTELECTO, FANTASMAS, ALMAS EN PENA, ESCRITURA, REVELACIÓN, CULTO INTERIOR.

\begin{abstract}
In antiquity, in the axial age, the maturity of the spirit (pneuma) and of the intellect (nous) and the generalization of writing take place. Then religion, which had the form of rite, law and doctrine, takes the form of inner worship.
\end{abstract}

\section{KEY WORDS}

PNEUMA, NOUS, SPIRIT, INTELLECT, GHOSTS, SOULS IN PAIN, HOLY SCRIPTURE, REVELATION, INTERIOR WORSHIP. 


\section{El ESPÍRITU Y LOS ESPÍRITUS EN EL MUNDO ANTIGUO.}

\section{I.1. ALMAS Y ESPÍRITUS EN LA VIDA DIARIA. LÉXICO DE LA ANTROPOLOGÍA PRE-HISTÓRICA.}

El culto interior, la oración de la que hablan y practican los antiguos, y que Jaspers toma como punto de referencia para caracterizar la era axial, ${ }^{1}$ no es algo que se pueda dar, sin más, en un ser humano de cualquier época. El chamán paleolítico, o los cazadores recolectores contemporáneos, pueden hacer viajes astrales, identificarse con los espíritus animales y conducir a las almas en pena, pero no encontrarse con Dios en el centro de sí mismos.

El ser humano es una unidad, un viviente unitario. En el principio era el cuerpo en movimiento, y así aparece en todas las experiencias y expresiones más primitivas. ${ }^{2}$ Una parte de ese ser humano corpóreo es un principio que le hace moverse, actuar, y, en general, vivir. Los hombres de las tribus de cazadores recolectores saben que hay un momento a partir del cual ese hombre ya no realizará más esas actividades. Es la muerte, y saben que el principio que le hacía vivir ya no está allí, en el cuerpo, y el cuerpo queda rígido, inerte.

La experiencia de la muerte no es la experiencia de que al viviente se le amputa el cuerpo o de que al cuerpo se le amputa otra cosa. Es la experiencia de la desaparición de la vida en el cuerpo. El cuerpo se descompone y hay alguna otra cosa que continua con otro tipo de actividad. Esa otra cosa recibe en las diferentes culturas un nombre, que se suele traducir a las lenguas europeas actuales por «alma» o por «espíritu» indistintamente.

Entre los mapuches, ${ }^{3}$ el alma es el lawe, por la cual el hombre tiene mongen, salud-vida. Se mantiene en buenas condiciones cuando recibe bien la luz y la energía del sol, Antü. Cuando no recibe bien la luz y energía del sol, se debilita su decisión firme y voluntaria (yafiduami), y también se debilita su yo, la vigilancia y atención a sí mismo (inche), y entonces el control de su mente (rakiduam), su corazón (pinke) y su cuerpo (kalül), es tomado por poderes ajenos o voluntades extrañas, los wekufe.

Cuando ocurre eso el hombre está enfermo, poseído por una entidad autónoma inteligente a la que se le expulsa dándole órdenes. Entonces se acude a quien puede curar, al ampife, o sea, a la persona que «puede dar órdenes con su palabra» (pife) al am, al doble etéreo del alma (lawe, principio de salud-vida).

1 Jaspers, Karl, Origen y meta de la historia, Madrid: Alianza, 1980.

2 Ragazzi, G., «La danza perpetua. Gesto, spazio sacro, rappresentazione e linguaggio nell'arte rupestre della Valcamonica», in The Importance of Place. The Site, the Message, the Spirit, Valcamonica Symposium '92, pp.76-85, 1992.

3 Mora Penroz, Ziley, El arte de sanar de la medicina mapuche, Santiago de Chile: Uqbar editores, 2013; cfr. Filosofía mapuche. Palabras Arcaicas para Despertar el Ser, Concepción, Chile: Editorial Kushe, 2001. 
Quien puede curar así, quien actúa como ampife, es sobre todo la mujer chaman (machi), la cual, mediante sus cantos, ensalmos y órdenes, captura a los poderes ajenos que controlan al enfermo, los expulsa, y concita a los poderes de los buenos espíritus ( pellu) para que le devuelvan la fuerza al pellu del enfermo. Entonces el pellu del enfermo se robustece y llena de salud-vida (mogen) el alma (lawe). El pellu es la llama interna de la vida humana, nace del sol y es inmortal.

Es posible que estos términos sean anteriores a la formación del lenguaje ordinario en el neolítico y calcolítico, y que pertenezcan al léxico de las voces, gritos y cantos de los rituales paleolíticos. Incluso es posible que algunos de ellos pertenezcan al léxico de los sapiens que salieron de África en la migración de hace setenta u ochenta mil años. ${ }^{4}$

El «alma» del ser humano de los mapuches tiene sus modalidades análogas en el kami de los japoneses o el $k a$ de los egipcios. ${ }^{5}$

El vocabulario antropológico más primitivo designa la vida paleolítica según la experiencia que hasta entonces hay de ella, e igualmente el léxico neolítico. El alma es principio de vida, está en la sangre y en el aire, y se va cuando el viviente muere y no respira. El alma-espíritu de la machi puede separarse del cuerpo en el trance, socorre al alma-espíritu en pena, gestiona los poderes de la naturaleza, la lluvia, la pesca, la caza, las enfermedades, y conoce los poderes de las piedras, las plantas y los animales, porque tiene trato con el pellu de las piedras, las plantas y los animales. ${ }^{6}$

En el calcolítico empieza a haber experiencias nuevas y aparecen nuevos aspectos y capacidades en la acción humana que se manifiestan en el vocabulario antropológico. En el Libro de los muertos, especialmente en el capítulo 188, aparecen $D e t$, cuerpo; $I b$, corazón, sede de la vida consciente, la conciencia, la razón y los deseos; $K a$, alma; $B a i$, doble del alma, $A k h$, alma separada; $R e$, nombre y Khabit, sombra. ${ }^{7}$

4 Es posible que varios de estos términos se correspondan con algunas de las 27 raíces de palabras del milenio setenta, que se conservan en la mayoría de las lenguas actualmente habladas según Ruhlen. Se ha tratado de este tema en Choza, J., Filosofía de la Cultura, (FC), Sevilla: Thémata, 2014, § 20.

5 Pagano, Maurizio, Lo spirito. Percorsi nella filosofía e nelle culture, Milano: Mimesis, 2011.

6 Menard, A., Sobre la vida y el poder de las piedras: Newenke kura en el Museo Mapuche de Cañete. Colecciones Digitales, Subdirección de Investigación, Servicio Nacional del Patrimonio Cultural, 2018.

7 Cfr. Alesssandro Bongioanni, Modalità dello spirito nell'antico Egitto, en Pagano, M., Lo spirito. Percorsi nella filosofia e nelle culture, Milano: Mimesis, 2011; cfr., El libro de los muertos, Ed, de Federico Lara Peinado, Madrid: Tecnos, 1993. 
Esas nociones y los términos correspondientes se encuentran también en el vocabulario antropológico de las culturas china, hindúes, iranias y en la Biblia judía, en el calcolítico, cuando el intelecto se emancipa de la imaginación y se forman las lenguas indoeuropeas. Como es obvio, se encuentran en todas las culturas antiguas, y en el universo lingüístico greco-romano, que constituye la matriz del mundo cultural del occidente contemporáneo.

La correspondencia entre el vocabulario antropológico paleolítico, neolítico, calcolítico y contemporáneo se puede percibir en el siguiente cuadro.

Términos antropológicos del lenguaje ordinario

\begin{tabular}{|l|l|l|l|}
\hline $\begin{array}{l}\text { Europeos mo- } \\
\text { dernos }\end{array}$ & Mapuches & Egipcios antiguos & Griegos / romanos \\
\hline Espíritu & Pellu & Akh & Pneuma/Spiritus \\
\hline Mente & Rakiduam & $\begin{array}{l}\text { Re, (nombre)/(pa- } \\
\text { labra })\end{array}$ & $\begin{array}{l}\text { Nous/Logos//Intellectus/ } \\
\text { Verbum }\end{array}$ \\
\hline Yo & Inche & Khabit, (Sombra) & Ego/Ego \\
\hline Alma & Lawe & Ka & Psique/Anima \\
\hline Doble del alma & Am & Bai & Daimon/Daimon \\
\hline Vida & Mogen & Anj o Anhk & Dsoé, Bios/ Vita \\
\hline Cuerpo & Kalül & Det & Soma, Sarx// Corpus, Caro \\
\hline Corazón & Pinke & Ib & Kardía/Cor \\
\hline
\end{tabular}

\section{2.- ALMAS Y ESPÍRITUS EN LA VIDA PÚBLICA. \\ HaLLOWEEN, ANTESTERIA Y DÍA DE MUERTOS.}

La Fiesta de los Muertos, de los difuntos o de los antepasados es, probablemente, una celebración en honor de los progenitores y ancestros, que se establece con los asentamientos urbanos neolíticos en numerosas culturas, y que en los procesos calcolíticos de urbanización se institucionaliza, adoptando configuraciones particulares en los que se advierten elementos articulado según una estructura común.

Suele celebrarse después de la cosecha en el otoño. El Wag del Antiguo Egipto se celebraba en agosto, el Bon del Japón budista tiene lugar en julio o agosto, el Pitri Paksha hindú en septiembre. En la religión Inca, el mes de noviembre entero es 'Ayamarca', que significa Fiesta de los Muertos, y en la China budista se le llama Fiesta de los espíritus. ${ }^{8}$

8 https://en.wikipedia.org/wiki/Festival_of_the_Dead 
En la Europa de tradición celta y cristiana el Halloween se celebra a principios de noviembre. En la tradición gaélica se llama Samhain, y en la cristianoescocesa se denomina All Hallows' Eve, esto es, «Día de todos los santos». En el Halloween, los tres días de fiesta podrían ser una conmemoración ritual del Diluvio, en el que se relata la debilidad de la tierra en el periodo anterior. ${ }^{9}$

La noche del 31 de octubre al 1 de noviembre es la celebración del final de la temporada de cosechas en la cultura celta y era considerada como el «Año Nuevo Celta», que comenzaba con la estación oscura. Es tanto una fiesta de transición (el paso de un año a otro) como de apertura al otro mundo. Su etimología gaélica significa 'fin del verano'.

Los rituales y el conjunto de elementos folklóricos del Halloween se difunden en todo el territorio de los Estados Unidos desde el siglo XVIII, y a partir de ahí se difunden por todo el mundo. En la actualidad el Samhain lo celebran de un modo muy particular los seguidores de movimientos religiosos neopaganos, como la wicca y el druidismo. ${ }^{10}$

La Antesteria, de ánthos (öv $\theta 0 \varsigma$, «flor») parece ser una fiesta jónica calcolítica de los difuntos, integrada en los ritos dionisíacos a partir de la antigüedad. Algunos autores la interpretan como Fiesta de la Revocación ( $\alpha v \alpha \theta \dot{\varepsilon} \sigma \sigma \alpha \sigma \theta \alpha 1$, anathessasthai, «orar») en referencia a los momentos de la celebración en que se consideraba que los muertos andan entre los vivos. Otros interpretan la fiesta como cultos para calmar y reconciliar a los difuntos. ${ }^{11}$

Tiene también tres etapas en tres días sucesivos, llamados Pithoigia, (fiesta de la «apertura de las jarras» de vino nuevo), Choës, (fiesta de «el vertido» de las jarras y de la bebida del vino nuevo) y Chytroi, (fiesta de «las ollas» o las «cacerolas»), en las que se ofrecían alimentos a Hermes Ctonio y a los difuntos.

Los difuntos, tanto Keres (Kñ $\rho \varepsilon \varsigma$, espíritus femeninos) como Cares (Kã $\rho \varepsilon \varsigma$, espíritus masculinos), que habían tenido una muerte violenta o habían quedado insepultos, permanecían comiendo y bebiendo las ofrendas que les ofrecían los celebrantes.

En la Grecia antigua hay un dicho que se dirige a los que piden favores con demasiada insistencia, «Vete a la calle, Keres, que ya se terminó la Antesteria». ${ }^{12}$

Probablemente la fiesta de difuntos contemporánea más vistosa, y que reproduce más literalmente la relación de los antiguos con los espíritus, es la fiesta del Día de Muertos en México.

El Día de Muertos tiene lugar el 1 yel 2 de noviembre y está vinculado a las celebraciones católicas de Día de los Fieles Difuntos y Todos los Santos. En

9 https://en.wikipedia.org/wiki/Halloween

10 https://en.wikipedia.org/wiki/Wicca

11 https://en.wikipedia.org/wiki/Anthesteria

$12 \mathrm{https} / / /$ en.wikipedia.org/wiki/Anthesteria 
el 2008 la Unesco declaró la festividad como Patrimonio Cultural Inmaterial de la Humanidad de México. ${ }^{13}$

El pueblo teotihuacano, los totonacas, los mexicas y aztecas, hacen continuamente ofrendas a los difuntos de comidas, bebidas y herramientas útiles para el viaje al más allá, y sacrifican perros en sus tumbas para que les sirvan de guías en el viaje.

En la actualidad en el Día de Muertos se hacen altares en las plazas y calles de las ciudades, y en ellos se disponen las comidas y bebidas que más agradan a los difuntos. Estos difuntos suelen ser padres, abuelos o bisabuelos, cuyos nombres, costumbres, gustos y aficiones se recuerdan y se procura satisfacer.

Se convive con ellos durante las fiestas como en la Antesteria griega, se canta, se baila, se interpretan piezas musicales con bandas de variados y numerosos instrumentos. Muchos de los participantes pasan la noche en los cementerios, que llenan de flores y de velas, para señalar a sus difuntos el camino hacia el más allá y hacerles compañía durante esas horas.

Hay numerosas grabaciones disponibles en la red, que se pueden estudiar todo lo detalladamente que se quiera, y, por supuesto, se puede participar en la fiesta en cualquier ciudad mexicana los días 1 y 2 de noviembre. ${ }^{14}$

Ahora lo que interesa es ver con qué nombre se designa a estos espíritus, de cuántos tipos son, qué trato hay con ellos y que estatuto ontológico les asigna la reflexión filosófica, para examinar la continuidad del léxico antropológico paleolítico y neolítico con el de la antigüedad y la época histórica, hasta nuestros días.

\section{3.- ALMAS, FANTASMAS Y DÁIMONES EN LOS RELATOS. Plutarco y TeRTUliano.}

Los espíritus de los difuntos con los que tratan los vivos en las fiestas de los antepasados, son, en primer lugar, espíritus de seres humanos iguales a los vivientes que celebran. Pero no son seres humanos completos como lo son los celebrantes, sino precisamente «espíritus».

Son seres humanos sin cuerpo, a los que se denominan unas veces de una manera y otras de otra, y esa nomenclatura es importante para analizar la congruencia entre lo que la razón práctica conoce y designa en la vida diaria, y lo que la razón teórica de los filósofos y teólogos de la época define y describe como elementos y estructura de la subjetividad humana.

En primer lugar, la vida cotidiana se expresa en el arte, en las historias y crónicas, en las causas judiciales y en el teatro y la novela. Y los elementos

13 https://es.wikipedia.org/wiki/Dia_de_Muertos

14 https://www.youtube.com/watch?v=DQrqVq5nf34; https://www.youtube.com/ watch?v=T9aMx6wXYcU 
descritos en esos fenómenos y episodios, se recogen en la reflexión teórica para elaborar doctrinas científicas y ortodoxias religiosas sobre lo humano y lo divino.

En las sociedades urbanas del siglo XXI tiene vigencia general un sentido común expresado en el lenguaje ordinario, que corresponde a una interpretación pública de la realidad metafísico-empirista, inspirada en la ciencia, y en el que no hay espíritus. A la vez, hay un sentido común, expresado también en el lenguaje ordinario, que corresponde a otra interpretación pública de la realidad metafísico-espiritualista, inspirada en el arte y en la experiencia común de la vida, en la que sí hay espíritus, y que queda desplazada al margen de la otra.

La primera es la interpretación pública de la realidad con mayor vigencia, y la segunda, aunque puede ser muy general, es más bien privada. La reflexión de la razón teórica, filosófica y teológica, y la construcción de la ortodoxia, es un tercer mundo-lenguaje, que intenta dar cuenta de los dos mundo-lenguajes anteriores.

La incompatibilidad entre estos tres mundo-lenguajes que se dan en las sociedades urbanas del siglo XXI, se intenta salvar apelando, desde un punto de vista político, al respeto a las minorías y a las otras culturas, desde un punto de vista cultural común, apelando al respeto al otro, a la persona y a las culturas, y desde el punto de vista culto-académico, apelando al punto de vista del nativo, al conocimiento local, o a la hermenéutica y la comprensión como forma máxima del saber.

Estas disonancias ontológicas entre los tres mundo-lenguajes, y sus intentos de solución, no afectan al léxico antropológico, sino solo y justamente a la ontología de sus significados y referentes. El léxico mantiene su continuidad desde la prehistoria hasta el final de la época histórica, y es una buena guía para salvar las incompatibilidades entre los tres mundo-lenguajes en los que viven las sociedades urbanas del siglo XXI.

Para advertir esa continuidad del léxico antropológico, se va revisar muy someramente, en primer lugar, el de los relatos, y después el de la elaboración de la antropología filosófica y teológica de la época histórica.

Los maestros del platonismo medio, especialmente Numenio de Apamea, por una parte, y Plutarco y Apuleyo, por otra, son los autores clásicos que más se ocupan de las almas de los difuntos, o «fantasmas», y, en cierto modo, los iniciadores de lo que más adelante será la angelología, la teología de los espíritus o de los «dáimones», como se les denomina en los medios culturales socráticos.

En la vida cotidiana las almas de los muertos mantienen un diálogo con los vivos más o menos asiduo. Este diálogo tiene periódicamente cada año un momento de culminación en el día de los difuntos en las diferentes culturas, como se ha señalado. 
Las almas de los difuntos, los fantasmas o almas en pena, de los que escriben Plutarco y Tertuliano, no son seres inexistentes. Son reales, pero no vivientes orgánicos. Y no son vivientes orgánicos porque, aun siendo el alma un principio vital, no está unida a un cuerpo, y no generan e infunden en el cuerpo el fluido vital, la sangre.

Cuando Ulises, Eneas y otros héroes viajan al Hades y se encuentran con las almas de los difuntos, pueden hablar con ellos si vuelven momentáneamente a una cierta vida mediante la ingestión de sangre. Tireseias y la madre de Ulises pueden hablar porque beben sangre.

La experiencia de la muerte es la experiencia paleolítica más intensa del alma. El chamán tiene entre sus funciones la de psicopompo, y tiene que conducir a las almas en pena a su lugar de descanso, como se hace en el neolítico y calcolítico en las fiestas de difuntos. Esas almas en pena son el lewa mapuche, el $k a$ egipcio o la psique griega, pero en ningún caso el pellu mapuche, el akh o el re egipcios, ni el nous o el pneuma griegos (\$30). Las almas en pena ( $p$ sique) lo son porque quedan heridas e incompletas, $\mathrm{y}$ tienen por eso un tipo de padecimiento que no pueden tener el intelecto (nous) o el espíritu (pneuma).

Cuando describen las fiestas de la antesteria, Plutarco y Tertuliano llaman almas en pena y fantasmas, al alma (psique) del difunto a la que quizá se mantiene unido el espíritu (pneuma y nous), sin su cuerpo (soma o sarx). Estas almas se relacionan con los vivos según protocolos bien establecidos, pero también con toda naturalidad y libertad.

El alma en pena es designada por Plutarco, unas veces con el término $p s i-$ que, sin más, otras veces con el término eidolón, que se traduce por «fantasma», y otras veces con el término phásmati que se traduce por «espectro». ${ }^{15}$ Junto al «alma» aparece con frecuencia el «daimon», que es siempre un doble espiritual del difunto, diferente pero asociado a él, a su personalidad y a su destino.

El daimon de Plutarco es el daimon que parece en los diálogos socráticos. Corresponde a la divinidad personal asociada indisolublemente a cada ser humano, a cada ser viviente o a cada entidad real, en la religión sumeria y la babilonia, pero también en el hinduismo y el shinto japonés, e incluso entre los mapuches, y que tiene su equivalencia en el ángel de la guarda del judaísmo, del cristianismo y del islam.

En la obra de Plutarco Cimón, el protagonista Pausanias, mata por error a una doncella bizantina de nombre Cleonice, y buena parte del drama consiste

15 Plutarco, Cimón, 6. 4-6, en Vidas paralelas, Vol. IV, Madrid: Gredos, 2009. Sigo la traducción de Dámaris Romero González, Seminario en la Facultad de Filosofía de Sevilla, el jueves 7 de mayo de 2017. Agradezco a Dámaris sus aclaraciones sobre la terminología de Plutarco y sobre su presencia en la obra de Tertuliano y en la de Carl Gustav Jung. Sobre la presencia de éstos y otros autores en la obra de Jung, cfr., Del Moral, Maite, La luz de la oscuridad, Madrid: Plaza y Valdés, 2017. 
en las relaciones entre Pausanias y el alma de Cleonice, a la que se designa con los términos anteriormente indicados: psique, eidolon, y phásmati. En el caso de Cimón, estos tres términos siempre son sinónimos y siempre designan el alma de Cleonice.

En otras obras de Plutarco, y de Tertuliano, esos tres términos no son sinónimos. A veces los fantasmas o los espectros no son almas de personas muertas, sino que son seres satánicos o completamente ficticios.

Las almas de los difuntos que están en pena, y que vuelven una y otra vez al diálogo con los vivos, son almas incompletas porque sus vidas acabaron abruptamente. No son en ningún caso espíritus, aunque vayan acompañadas de ellos, no son nous ni son pneuma, que siempre son entidades completas y están «separadas», según la escuela aristotélica, desde Aristóteles hasta Avicena, Tomás de Aquino, Brentano y Edith Stein, y según las escuelas neoplatónicas.

En el capítulo LVI del De Anima, Tertuliano agrupa los diversos tipos de almas en pena, que se encuentran frecuentemente en las fiestas de difunto griegas y romanas, en cuatro grandes categorías: en primer lugar, las de las personas, más frecuentemente mujeres, que han muerto solteras. En segundo lugar, las de las que mueren en la infancia, las de los niños, a los que a veces se asimilan algunos soldados. En tercer lugar, las de las personas que mueren de muerte violenta, entre las que se cuentan los militares, soldados, combatientes, malhechores, etc. Y en cuarto lugar, las de las personas que mueren sin sepultura y quedan desasistidas de los suyos. ${ }^{16}$

\section{4. ALMAS, FANTASMAS Y DÁIMONES EN LA REFLEXIÓN. DE ARISTÓTELES A EDITH STEIN.}

La descripción de las características del espíritu, y de los espíritus, se lleva a cabo, a partir de la era axial, desde el puno de vista de la interioridad subjetiva, que es de la fenomenología, el de la experiencia interior, y desde el punto de vista de la interioridad objetiva, que es el de la ontología, de lo que las cosas son en sí según las puede concebir el intelecto.

La elaboración doctrinal del estatuto ontológico de los entes espirituales tiene lugar inicialmente en la práctica religiosa y en los relatos y, a partir de ahí, en la reflexión filosófica que va desde Sócrates, Platón y Aristóteles hasta los pensadores judíos del siglo XX, especialmente Edith Stein.

En el neolítico la mente se despliega como imaginación y los relatos (los mitos) son solamente imaginativos. En el calcolítico empiezan a ser también 
intelectuales, y empieza a haber geometría, aritmética, lenguaje escrito, sentido del tiempo y de la eternidad. ${ }^{17}$

La diferencia entre el alma y el espíritu se esboza y se perfila en el calcolítico. La noción de un elemento espiritual que vive la vida de los dioses, pneuma, distinto de la psique, que organiza el cuerpo orgánico y le da vida, se encuentra en el uso del lenguaje durante el periodo homérico. ${ }^{18}$

La noción de intelecto espiritual, nous, que puede ser inmortal y que unas veces se identifica con el pneuma y con Zeus, y otras no, se encuentra a partir de Anaxágoras y de Heráclito, ${ }^{19}$ y su elaboración ontológica la inician Platón y Aristóteles.

El intelecto o nous, el espíritu, es descrito por Aristóteles como «separado», y como lo único «divino e inmortal en el hombre». Platón y Aristóteles diferencian tres psique o almas, a saber, alma vegetativa, alma sensitiva y alma intelectiva. En las glosas y comentarios posteriores queda claro que el alma intelectiva es el intelecto, el nous, que tiene al menos dos partes, intelecto agente y el paciente, y que el intelecto agente se designa también con el término pneuma.

En este estudio se utiliza el termino nous como sinónimo de intelecto, de espíritu intelectual o de espíritu racional, que genera y despliega el logos, la palabra y los razonamientos, y el término pneuma como sinónimo de espíritu personal, que desde el centro del sí mismo, o del corazón, quiere reflexivamente y ama espontáneamente, que vive la experiencia mística.

A partir de las enseñanzas del Liceo y de la escuela de Atenas, y a partir de la difusión del cristianismo, se debate y se clarifica qué hay que entender por inmortalidad del alma. En esos debates «alma» se designa con el termino psique, y no con el término nous ni con el término pneuma. Entonces el espíritu tiene por primera vez experiencia de sí mismo y de su fundamento y describe esa experiencia. Es el momento en que el nous queda deslumbrado de sí mismo y por sí mismo, como dice Filón. ${ }^{20}$

A partir de entonces en el lenguaje ordinario y en el filosófico, se habla diferenciadamente de psique, nous y pneuma porque hay experiencia diferen-

17 Choza, J., La revelación originaria: la religión de la edad de los metales, Sevilla: Thémata, 2018, §§ 22-24.

18 Cfr. Magris, Aldo, Lo «spirito» e l'eredità dei greci, en Pagano, Maurizio, Lo spirito. Percorsi nella filosofía e nelle culture, Milano: Mimesis, 2011. Cfr., Bremmer, Jan N., El concepto del alma en la antigua Grecia, Madrid: Siruela,

19 De tales a Demócrito. Fragmentos presocráticos, Madrid: Alianza, 1988; Heráclito, Frag. 84 (32)

20 Garay, Jesús de, «La extrañeza del Nous en Filón de Alejandría», Anuario Filosófico, $2000,(33)$,

203-216. 
ciada de alma, intelecto y espíritu. Estos tres términos se encuentran así en el griego y el latín clásicos, y pasan así a las lenguas europeas modernas para designar elementos y actividades diferenciadas del ser humano.

Además del espíritu (pneuma) humano, hay espíritus (pellu mapuche, $a k h$ egipcio y pneuma griego) de las piedras, las montañas, los ríos, bosques, de todos y cada uno de los vivientes y de todos y cada uno de los astros, en todas las culturas de la prehistoria, y en las de la antigüedad y el medievo en la época histórica.

Estos espíritus son los dobles de esas almas reales, llamados «ángeles» de esos entes en el mazdeísmo, judaísmo, gnosis, cristianismo e islam. Estos espíritus se relacionan entre sí y actúan a favor o en contra del hombre, según las prácticas de los chamanes, exorcistas, sacerdotes y taumaturgos.

La interrelación entre todos estos entes, la correspondencia entre esferas, astros, animales y plantas, que es el fundamento de las formas de la magia, y del sistema de los sacramentos de las distintas religiones, se expuso en otro luga ${ }^{21}$ y su ontología se verá en otro diferente.

Además de los espíritus ( pneuma) de todos y cada uno de los entes, las culturas prehistóricas, y la antigua y medieval de la época histórica, describen la actividad de otros espíritus cuya actividad consiste en la formación y regulación del universo, y en la alabanza del creador.

Estos espíritus son, por una parte, los entes intermedios entre el Uno generador y el cosmos generado, descritos en las doctrinas de Platón y los neoplatónicos. Por otra parte, son las esferas celestes de la Física de Aristóteles y los astros del mazdeísmo, de los que hablan igualmente los Oráculos caldeos y las doctrinas gnósticas. Y, por otra parte, son las jerarquías de ángeles del mazdeísmo, judaísmo, cristianismo e islam. Estas criaturas espirituales, aunque diferentes entre sí, pertenecen a un mismo grupo de familias ontológicas, teóricas y eidéticas.

Hay una diferencia importante entre el estatuto ontológico de los espíritus de los entes materiales, entre los que se cuentan las almas en pena, y el de las criaturas espirituales, que son completas en sí, y tienen su legitimidad y plenitud en el mundo que les es propio.

Las almas separadas tienen un estatuto propio, y se dividen en dos grandes clases, las que han alcanzado su descanso y las que vagan penando en busca de lo que les falta o lo que se les debe.

Estas últimas son las que el chamán paleolítico reconduce a su descanso, y que en las prácticas de la memoria épica neolítica se representa mediante

21 «La correspondencia entre esferas, astros, animales y plantas», Choza, J., El culto originario: la religión paleolítica. Magia y sacramentos, Sevilla: Thémata, 2016, $§ 31$. 
la piedrecita del juego de la rayuela, como se estudió en otro lugar. ${ }^{22}$ Por otra parte, estas son la mayor parte de las almas con las que se trata en las fiestas de los difuntos, desde la Antesteria griega hasta el Día de muertos de México.

El estatuto ontológico de estos espíritus, el tipo de realidad que tienen o que son, depende del modo en se imaginaron y entendieron en el calcolítico la categoría lingüística de sustancia, que se ha examinado en su momentos (ROREM §§ 23 y 51-61), y del modo en que se elabora y entiende la categoría y la noción filosófica de sustancia (ousia, hypóstasis) .

Esta noción filosófica depende, por una parte, de las categorizaciones calcolíticas imaginativas e intelectivas indicadas, y, por otra, de las elaboraciones conceptuales reflexivas realizadas en la escuela de la Atenas clásica, especialmente por parte de Aristóteles, y que ha registrado diversas y controvertidas interpretaciones en la historia de la cultura occidental.

Aristóteles considera que solo una parte del alma ( $p$ sique), de esa substancia que son los seres humanos, seres temporales y corruptibles, sólo la parte denominada espíritu (nous y/o pneuma), que es incorruptible y está separado del resto de las partes del hombre, es inmortal.

Por su parte, Proclo en el siglo V, y los árabes que resumen su doctrina en el siglo X o en el XI en el Libro de las causas (Liber de causis), consideran que todo viviente, toda sustancia viviente, tiene un alma inmortal, porque la sustancia no pertenece al orden o a la categoría del tiempo, sino a la de eternidad. Esta doctrina la sigue Tomás de Aquino en el siglo XIII, ${ }^{23}$ la recoge y la refuerza Franz Brentano en el siglo XIX, la asume y la difunde Edith Stein en el siglo XX, ${ }^{24}$ y la retoman algunos movimientos animalistas en el siglo XXI.

Independientemente de las almas (psique) de los entes corpóreos, para las culturas prehistóricas y las de la época histórica, y para la filosofía de la época histórica, con excepción de una parte de la filosofía moderna, ${ }^{25}$ son sustancias los espíritus (pneuma) de las ninfas, hadas, gnomos, y los kami de todas las plantas, y, por otra parte, son sustancias los espíritus (pneuma) no asociados a los entes materiales, como lo ángeles y demonios, con sus jerarquías respectivas.

Estos seres espirituales son sustancias completas desde el principio, porque nunca han tenido cuerpo (soma, sarx) ni han pertenecido al orden del tiempo, y regulan el cosmos desde fuera del tiempo, con la fuerza de su pensamiento.

22 «El juego de la rayuela y la geometría sagrada», Choza, J., El culto originario: la religión paleolítica. Magia y sacramentos, Sevilla: Thémata, 2016, § 29.

23 Tomás de Aquino, Exposición sobre el 'Libro de las Causas'. Introducción, traducción y notas de Juan Cruz Cruz, Pamplona, Eunsa, 2000.

24 Gutiérrez Aguilar, Ananí, La experiencia de la persona en el pensamiento de Edith Stein, Sevilla: Thémata, 2018.

25 Con la excepción de los filósofos materialistas y de Kant, que dedica unas cuantas páginas de su Antropología en sentido pragmático a ridiculizar la «creencia en los fantasmas». 
Y no han tenido nunca cuerpo (soma, sarx) porque nunca han tenido alma ( $p$ sique), que es el principio activo que organiza el cuerpo y lo hace viviente. ${ }^{26}$

Para los medios culturales urbanos del siglo XXI estas tesis filosóficas pueden sonar extrañas, porque, como se ha dicho antes, las poblaciones urbanas occidentales de los siglos XX y XXI viven simultáneamente en dos mundo-lenguajes incomunicables entre sí: el del lenguaje ordinario, cuyo léxico dispone de términos para designar «realidades» como conciencia, intimidad, alma, vida, y el lenguaje de la ciencia, que no dispone de esos términos ni de ningunos equivalentes, para hacer referencias a esas entidades que, por tanto, desde el punto de vista de la ciencia, son «inexistentes».

No es que la ontología del lenguaje científico sea necesariamente «agnóstica», es, sencillamente y por el momento, incompatible con un discurso basado en una ontología no empirista, como es la del lenguaje ordinario.

A veces, según las diferentes áreas culturales, las diferentes décadas de los siglos XX y XXI, los diferentes grupos y los diferentes individuos, se da la actitud «agnóstica» del antropólogo, el etnógrafo, el fotógrafo y el periodista, que suspenden el juicio sobre la ontología del doble lenguaje que utilizan, y se atienen al punto de vista del nativo, o se atienen, como se ha dicho, al conocimiento local. ${ }^{27}$

\section{LA REVELACIÓN COMO PALABRA SAGRADA Y COMO ESCRITURA SAGRADA.}

\section{1. ORÍGENES Y LOS SENTIDOS DE LA ESCRITURA.}

Lo que se cuenta en los relatos, antes se celebra en las fiestas y en los ritos. Lo que se adora en la liturgia, se conoce y entiende en la meditación de la escritura y se comprende y ama en la meditación. Y eso, tanto si es el sacrificio del oso, el éxodo y la peregrinación por el desierto o la ayuda a los difuntos en la Antesteria.

Pero para alcanzar ese nivel de comprensión hace falta que, junto a la sensibilidad y el comportamiento de supervivencia de los cazadores recolectores, se desarrolle la imaginación simbólica en los asentamientos de los agricultores, llegue a su madurez el espíritu intelectual en los habitantes de los imperios, y alcance el sí mismo espiritual humano la plenitud propia de su esencia en los ciudadanos de la polis.

26 Edith Stein, Introducción a la filosofía, en Obras Completas, Burgos: Monte Carmelo, 2005, pag. 822, y Ser finito y ser eterno, México: FCE, 1996, capítulos VII y VIII.

27 Geertz, C., Conocimiento local: Ensayos sobre la interpretación de las culturas, Barcelona: Paidos Ibérica, 1994. 
Esa plenitud ya la tienen los ciudadanos de Atenas en el siglo IV AdC, Platón y Aristóteles entre ellos, y los de Alejandría en el siglo I y II dC, Filón de Alejandría y Orígenes entre ellos.

Esa madurez subjetiva, y esa historia transcurrida y asumida según sus estadios y etapas, descrita ya por Pablo de Tarso en sus Epistolas, es lo que le permite a Orígenes describir y sistematizar los cuatro sentidos de la escritura, en correspondencia con esos momentos de desarrollo de la psique y el espíritu humano. ${ }^{28}$

\begin{tabular}{|c|c|c|c|}
\hline \multicolumn{2}{|c|}{ Sentidos de la Escritura } \\
\hline $\begin{array}{c}\text { Literal } \\
\text { para la sensibili- } \\
\text { dad corporal) }\end{array}$ & \multicolumn{2}{|c|}{$\begin{array}{c}\text { Moral } \\
\text { (para el alma) }\end{array}$} & $\begin{array}{c}\text { Místico } \\
\text { (para el espíritu) }\end{array}$ \\
\hline $\begin{array}{c}\text { 1.- Literal históri- } \\
\text { co efectivo }\end{array}$ & $\begin{array}{c}\text { 2.- Literal históri- } \\
\text { co ficticio }\end{array}$ & $\begin{array}{l}\text { 3.- Místico Alegó- } \\
\text { rico. } \\
\text { Prefiguraciones } \\
\text { de Cristo y de su } \\
\text { Iglesia }\end{array}$ & $\begin{array}{l}\text { 4.- Místico Anagó- } \\
\text { gico. } \\
\text { Tipos en el mundo } \\
\text { celestial de los que } \\
\text { las cosas de este } \\
\text { mundo son antiti- } \\
\text { pos }\end{array}$ \\
\hline
\end{tabular}

1.- El sentido literal efectivo es el que se puede entender de modo inmediato y se refiere a cosas y eventos que se captan mediante los sentidos corporales. Es el sentido que tiene la historia efectiva de Jesús y los profetas, como la tiene también la de Moisés y Yahweh, la de Arjuna en el Bhagavad Gita, la de los héroes homéricos, la preincaica Leyenda de Manco Cápac y Mama Ocllo, o la del pueblo maya del Popol Vuh.

2.- El sentido literal ficticio es el propuesto o sugerido «por el Sagrado Espíritu para transmitir verdades morales o místicas, que las realidades terrenas no expresan suficientemente». Es el sentido que tienen las parábolas de Jesús $\mathrm{y}$ de los profetas.

En la ley moral, «algunos preceptos hay que observarlos en sentido literal, y otros, entenderlos en ese sentido sería absurdo o imposible, pero contienen una enseñanza moral o mística». Por ejemplo, «y si tu ojo te escandaliza, arráncatelo y tíralo lejos de ti. Más te vale entrar tuerto en la Vida, que con los dos ojos ser arrojado al fuego del infierno» (Mateo, 18:9). htm

28 Orígenes,Philocalia,I, 1, http://www.tertullian.org/fathers/origen_philocalia_02_text. 
3.- El sentido místico alegórico es el que tienen algunos episodios, literalmente acontecidos, pero que además describen categorías, momentos o etapas trascendentales de la existencia. Así, tienen un sentido alegórico episodios tan típicos de los libros sagrados como la salida del hogar primero, la formación del pueblo, la peregrinación hasta la nueva tierra, el sacrificio y la renuncia, la muerte y la marcha a los cielos.

Se trata de episodios que han ocurrido efectivamente, pero que además tienen un sentido paradigmático, permanente y ejemplar. Tanto en la Biblia de Orígenes como en los libros sagrados de la India, la Grecia antigua, o la cultura quechua. En todos esos relatos la comunidad tiene un comienzo y una historia. La historia puede ser una peregrinación en sentido literal y en sentido alegórico, en la que es conducida por la divinidad misma hasta la felicidad definitiva y permanente.

4.- El sentido místico anagógico consiste en la comprensión de un acontecimiento empírico, descrito literalmente, como un acontecimiento celestial, eterno o definitivo. Así, la liberación del pueblo de la esclavitud del Faraón, significa la salvación definitiva. El socorro empírico al necesitado significa dicha eterna: «¿Cuándo te vimos enfermo o preso, y fuimos a verte?» Y el Rey les responderá: «Les aseguro que cada vez que lo hicieron con el más pequeño de mis hermanos, lo hicieron conmigo» (Mateo 25: 39-40).

También determinados eventos y comportamientos tienen un sentido eterno, como aparece en el discurso evangélico de las Bienaventuranzas:

«9 Felices los que trabajan por la paz, porque serán llamados hijos de Dios.

10 Felices los que son perseguidos por practicar la justicia, porque a ellos les pertenece el Reino de los Cielos.

11 Felices ustedes, cuando sean insultados y perseguidos, y cuando se los calumnie en toda forma a causa de mí.

12 Alégrense y regocíjense entonces, porque ustedes tendrán una gran recompensa en el cielo; de la misma manera persiguieron a los profetas que los precedieron» (Mateo 5:3-11).

Esta enseñanza y promesa de felicidad eterna se encuentra con el mismo tenor y sentido en los textos sagrados hebreos, mazdeistas, hindúes, y chinos, y pueden reconocerse literalmente en el Tao te ching de Lao Tse.${ }^{29}$ El espíritu,

«para aquellos que no pueden desarrollar el trabajo de investigar estos misterios, suministra las doctrinas antedichas [mística alegórica y mística anagógica] encu-

29 Cfr. Soublettte, Gaston, El cristo preexistente, Santiago de Chile: Cuatro Vientos, 1990. El libro contiene un análisis comparativo de los textos de las ocho bienaventuranzas de los evangelios cristianos con sus paralelos en el texto de Lao Tse. Agradezco a Alejandro Serani, de la Universidad San Sebastián de Chile, haberme dado a conocer esta obra y al autor de ella. 
biertas en versiones narrativas, proporcionando un relato de las cosas visibles de la creación, y de la creación del hombre, y de los descendientes de los primeros hombres hasta que llegan a ser muy numerosos.

En otras historias relata las acciones correctas de los hombres, y los pecados que ocasionalmente cometen en cuanto hombres, así como las debilidades, excesos y aberraciones de los hombres carentes de ley y de bondad.

Y por extraño que pueda parecer, mediante las historias de guerras y victorias y derrotados, algunos de los misterios inefables son declarados a quienes tienen habilidad para investigar estos asuntos.

Y lo que es más maravilloso todavía, a través de la ley escrita, quedan anunciadas las leyes de la Verdad. Y todos esos temas quedan articulados entre sí por la Divina Sabiduría, con un poder verdaderamente digno de la sabiduría de Dios. Porque es el propósito del Espíritu hacer incluso el revestimiento de las cosas espirituales, es decir, la parte 'corpórea' de las Escrituras, de modo que no resulte sin provecho, sino capaz de proporcionar un beneficio a la mayoría de los lectores según sus capacidades». ${ }^{30}$

\section{2. LA ORACIÓN COMO CULTO ESPIRITUAL INTERIOR.}

La oración es la versión espiritual del sacrificio. El sacrifico es la primera forma de afirmación de la vida, la primera forma de religión. La oración es la manera en que la voluntad humana se subroga en la divida y la asume, en su actividad de afirmación de la vida y de la totalidad de los entes reales creados en su ser, desde lo más profundo de su ser.

En su sentido más superficial, oración es la recitación de alabanzas y peticiones al fundamento del ser y de la vida, a los poderes sagrados, ya compuestas $\mathrm{y}$ recitadas por otras personas, privadamente o institucionalmente.

En su sentido más profundo es participar en la creación y en la redención, es cumplir el mandato «amarás pues al Señor tu Dios con todo tu corazón, y con toda tu alma, y con toda tu mente, y con todas tus fuerzas» (Levítico 19:18).

En su sentido superficial la oración es la celebración de un matrimonio que no se consuma, y en su sentido profundo es la consumación del matrimonio entre el hombre y Dios, que tiene como resultado precisamente la participación del hombre en la creación y la redención. La comparación es de Orígenes.

«Así como sin la mujer y sin las actividades requeridas para la procreación, el hombre no puede procrear, de la misma manera uno no puede alcanzar ciertas cosas sin orar de una cierta manera, con una cierta disposición, con una cierta fe, con un cierto modo de vida previo. Por eso, no debemos balbucear, ni pedir 
cosas pequeñas, ni rezar para lograr cosas terrenales, ni orar con el ánimo airado o disturbado». ${ }^{31}$

Esa oración es el culto espiritual interior, el encuentro con lo divino en la intimidad personal, que tiene lugar según una sucesión de los cinco momentos o fases de la experiencia mística, que son los siguientes: 1) comprensión de lo divino como absoluto y como principio, 2) comprensión de la generación de la multitud de seres, 3) diferenciación entre el orden del ser y el orden del obrar en el mundo y en el hombre, 4) concentración del espíritu sobre sí y sobre su fundamento, y 5) identificación con el principio y armonía íntima con el principio y con todas las criaturas.

Estas fases o etapas describen el proceso del encuentro con lo divino y, en general, la relación íntima del hombre con lo divino en su relación con sus criaturas. Puede representarse y glosarle, según las diferentes religiones, en la siguiente tabla.

\begin{tabular}{|l|l|l|l|l|}
\hline $\begin{array}{c}\text { 1.- Princi- } \\
\text { pio. } \\
\begin{array}{c}\text { Lo divino } \\
\text { absoluto }\end{array}\end{array}$ & $\begin{array}{c}\text { 2.- Generación } \\
\text { de los seres }\end{array}$ & $\begin{array}{l}\text { 3.- Diferen- } \\
\text { ciación orden } \\
\text { de ser y obrar }\end{array}$ & $\begin{array}{l}\text { 4.- Concentra- } \\
\text { ción y retorno }\end{array}$ & $\begin{array}{c}\text { 5.- Identifica- } \\
\text { ción con el uno }\end{array}$ \\
\hline Tao & $\begin{array}{l}\text { Relaciones del } \\
\text { creador a las } \\
\text { criaturas, de } \\
\text { ellas entre sí, y } \\
\text { en su depender } \\
\text { del Principio }\end{array}$ & $\begin{array}{l}\text { Diferencia- } \\
\text { ción entre } \\
\text { acto primero, } \\
\text { del hombre y } \\
\text { del mundo, y } \\
\text { actos segun- } \\
\text { dos }\end{array}$ & $\begin{array}{l}\text { Concentración } \\
\text { del espíritu } \\
\text { sobre sí mismo } \\
\text { y sobre el fun- } \\
\text { damento de sí }\end{array}$ & $\begin{array}{l}\text { Identificación } \\
\text { con el Uno, Ser, } \\
\text { Vida, y armonía } \\
\text { ína con to- } \\
\text { das las criaturas }\end{array}$ \\
Uno & & & & \\
Dios & & & & \\
\hline
\end{tabular}

Ese culto espiritual interior puede tener dos formas, una la de su comprensión espiritual intelectual, en la teología mística, y otra la de su ejercicio espiritual existencial en la experiencia mística, y así se despliega en las diferentes religiones.

El desarrollo de la religión desde el paleolítico hasta la antigüedad, es el desarrollo del espíritu hasta encontrarse consigo mismo, hasta encontrar en el centro de su fondo el poder sagrado que fundamenta su vida y la de todas las realidades, y el de una unión y comunicación con él en virtud de la cual le acompaña en toda la tarea de la creación y la redención, y las celebra con él.

31 Orígenes, On prayer, 5 , cit. 
JACINTo ChOZA es catedrático emérito de la Universidad de Sevilla, España.

Lineas de investigación:

Antropología filosófica y filosofía de la cultura.

La moral originaria: la religión neolítica. Sevilla, Thémata, 2017.

La revelación originaria: la religión de la Edad de los Metales. Sevilla, Thémata, 2018.

Email: jacintochoza@gmail.com

Ananí Gutiérrez Aguilar es profesora titular de filosofía en la Universidad Nacional de San Agustín, Arequipa, Perú.

Lineas de investigación

Ética y fenomenología.

Publicaciones recientes:

Familia y valores. Principios del derecho de familia, Universidad Católica de Santa María, Arequipa, 2007.

La experiencia de la persona en el pensamiento de Edith Stein, Sevilla, Thémata, 2018.

Email: gutierrez.anani@gmail.com 